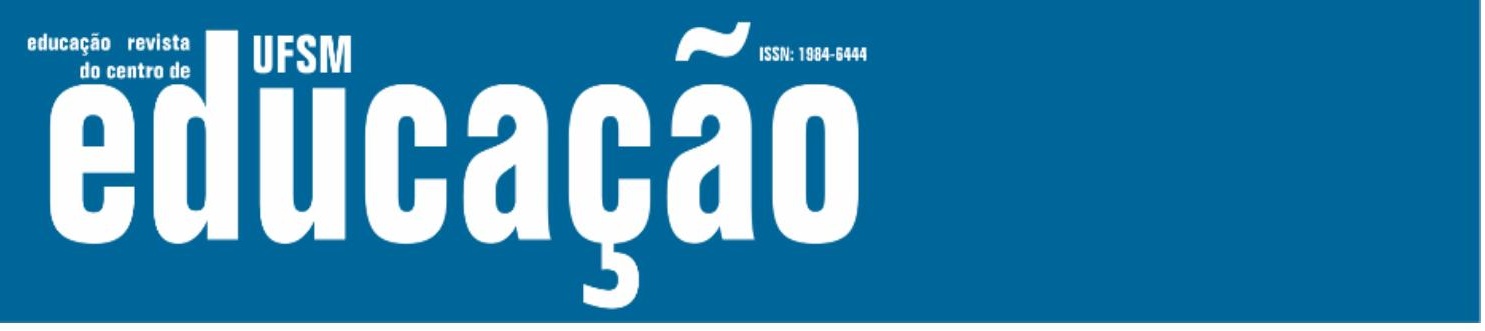

ISSN: 1984-6444 | http://dx.doi.org/10.5902/1984644448573

\title{
Base Nacional Comum Curricular (BNCC), bilinguismo, leitura em L2 e estratégias: abordagens e discussões
}

\author{
Base Nacional Comum Curricular (BNCC), bilingualism, L2 reading and \\ strategies: approaches and discussions
}

Aline Casagrande Rosso

Doutoranda na Universidade Federal do Rio Grande do Sul, Porto Alegre, Rio Grande do Sul, Brasil. prof.alinerosso@gmail.com - https://orcid.org/0000-0001-6498-5898

Ana Beatriz Arêas Da Luz Fontes

Professora doutora na Universidade Federal do Rio Grande do Sul, Porto Alegre, Rio Grande do Sul, Brasil.

ana.fontes@ufrgs.br - https://orcid.org/0000-0002-8075-5256

Recebido em 02 de agosto de 2020

Aprovado em 06 de novembro de 2020

Publicado em 04 de novembro de 2021

\section{RESUMO}

Esta pesquisa, de caráter bibliográfico e documental, visa esclarecer se e de que forma a Base Nacional Comum Curricular (BNCC) aborda os temas bilinguismo, leitura em L2 e estratégias de leitura no corpo do documento. Para tanto, foram analisados os cinco eixos organizadores da regulamentação que incluem oralidade, leitura, escrita, conhecimentos linguísticos e dimensão intercultural, com foco na leitura e nos seus desdobramentos: as unidades temáticas, os objetos de ensino e as habilidades, além das competências específicas de língua inglesa para o Ensino Fundamental. As conclusões apontam que o documento apresenta um debate válido sobre as habilidades que precisam ser desenvolvidas em sala de aula com relação ao desenvolvimento bilíngue, uma vez que traz ideias para o professor expandir as potencialidades linguísticas dos alunos. Todavia, o documento demonstra falhas quando não demonstra ter embasamento científico em suas afirmações, não desenvolve com propriedade os conceitos relacionados à leitura, bem como não deixa claro quais são os objetivos a partir da leitura em inglês como L2. Além disso, o caráter normatizador do documento faz com que o professor fique com a sua prática, de certa maneira, limitada, uma vez que a BNCC determina quais os conteúdos inerentes a cada ano escolar. Participam do debate teórico autores como Kleiman (1985; 2011; 2013), Souza e Garcia (2012), Alliende e Condemarín (2005), Craik, Bialystok e Freedman (2010), Godoy e Dias (2014), Santos (2013) e Grosjean (1997; 2012).

Palavras-chave: BNCC; Bilinguismo; Estratégias de leitura. 


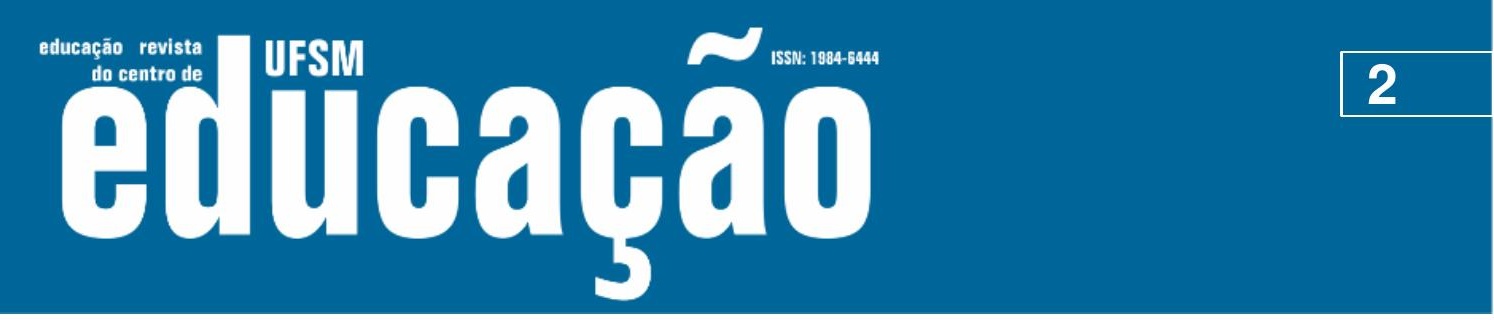

ISSN: 1984-6444 | http://dx.doi.org/10.5902/1984644448673

\section{ABSTRACT}

This research, of bibliographic and documentary character, aims at clarifying if and how the Brazilian Base Nacional Comum Curricular (BNCC) addresses the themes of bilingualism, additional language reading and reading strategies in the body of the document. To this end, the five organizing axes of regulation were analyzed, including orality, reading, writing, linguistic knowledge and intercultural dimension, focusing on reading and its consequences: the thematic units, teaching objects and skills, in addition to the specific skills of English language for the Elementary Degree. The conclusions suggest that the document presents a valid debate about the skills that need to be developed in the classroom regarding bilingual development, since it brings ideas for the teacher to expand the students' linguistic potentials. However, the document shows flaws when it does not demonstrate to have a scientific basis in its statements, does not properly develop the concepts related to reading, nor does make it clear what are the objectives from reading in English as L2. In addition, the document's normative character makes teachers' practice somewhat limited, since the BNCC determines the content inherent to each school year. Authors such as Kleiman (1985; 2011; 2013), Souza and Garcia (2012), Alliende and Condemarín (2005), Craik, Bialystok, and Freedman (2010), Godoy and Dias (2014), Santos (2013) and Grosjean $(1997 ; 2012)$ participate in the theoretical debate.

Keywords: BNCC; Bilingualism; Reading strategies.

\section{Introdução}

A educação brasileira vem, durante as últimas décadas, passando por estágios intermitentes de tentativas de sucesso, de modo que, de tempos em tempos, um novo documento norteador para escolas, gestores e professores aparece. Durante muitos anos (mais especificamente, no final dos anos 90 até meados de 2013, quando deuse início a elaboração do sucessor), os Parâmetros Curriculares Nacionais (PCN) guiaram o contexto escolar para alunos do Ensino Fundamental (Anos Iniciais e Anos Finais), ofertando orientações específicas para cada disciplina, que poderiam ser adaptadas à realidade de cada região ou comunidade em que a escola estava inserida (BRASIL, 1997). Em 2014, foi posto em vigência um documento chamado Diretrizes Curriculares Nacionais da Educação Básica (DCN), que, além de envolver o Ensino Fundamental, abrangia também o Ensino Médio. Este documento tinha por objetivo contribuir para "assegurar a formação básica comum nacional, tendo como foco os 


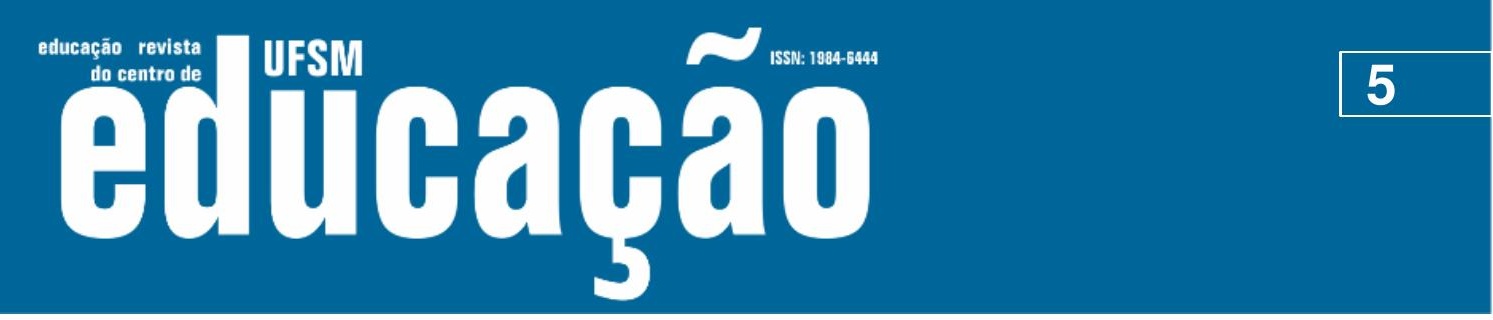

ISSN: 1984-6444 | http://dx.doi.org/10.5902/1984644448673

o teor da BNCC é um retrocesso em relação aos Parâmetros Curriculares Nacionais (PCN) de 1998, muito embora esse documento também adotasse como princípio organizador do currículo as competências. Além disso, entendemos que a BNCC é praticamente um documento "normativo" para a construção do currículo, alimentando enfoques prescritivos associados ao produtivismo e ao eficientíssimo do mundo contemporâneo comprometido com as avaliações (ORNELLAS; SILVA, 2019, p. 322-323).

O documento ainda é criticado por parte dos pesquisadores da educação. Micarello (2016) postula que a BNCC possui elementos que ameaçam o estado democrático; Orrú (2018) menciona que o documento está "à contramão dos espaços de aprendizagem inovadores e inclusivos" (ORRÚ, 2018, p. 139). Em linhas gerais, o documento, apesar de ter passado por consulta pública (BRASIL, 2017), parece conter limitações e inconsistências em muitas disciplinas curriculares, como Geografia (GUIMARÃES, 2018), História (SILVA, 2018), Educação Física (MARTINELI et al., 2016) e Língua Inglesa (RIBAS, 2018).

Por outro lado, alguns pesquisadores vêm apontando uma faceta mais positiva e branda sobre o documento. Fistarol, Fischer e Wenderlich (2019), por exemplo, dizem que o documento abre oportunidades para diferentes trabalhos, inclusive interdisciplinares, além de que proporciona um olhar mais atualizado da educação, uma vez que ressalta a importância do envolvimento das tecnologias nas práticas pedagógicas. Neira, Alviano Júnior e Almeida (2016, p. 40) concordam, e ainda salientam que a BNCC faz do professor um sujeito transformador, fazendo do aluno "alguém com consciência histórica e sensível às diferenças". Assim, em um processo coletivo, de diálogos e acordos, a escola se tornaria um local mais crítico e de combate às desigualdades.

Embora haja críticas ao documento, ele já está vigente em muitas instituições de ensino, e não é objetivo deste trabalho tecer mais questionamentos sobre ele. $O$ intuito desta pesquisa é averiguar se há menções na BNCC sobre leitura, estratégias de leitura e bilinguismo no que tange ao componente curricular Língua Inglesa. Mais do que isso, é também objetivo deste trabalho analisar, caso haja menções ou conceitualizações, de que maneira a BNCC aborda e/ou sugere o trabalho com os temas supracitados. Portanto, guiam este estudo os seguintes questionamentos: i) A Base Nacional Comum Curricular, no que tange à Língua Inglesa, faz menção e/ou 


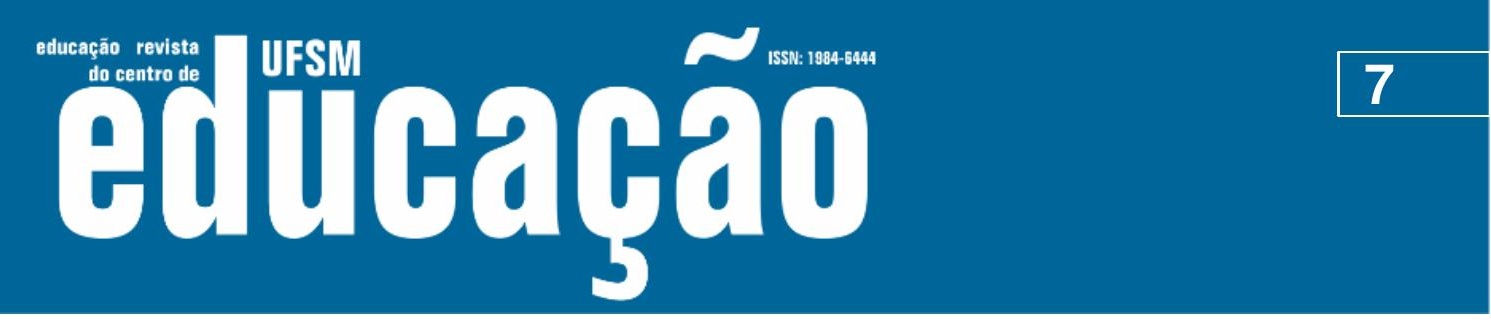

ISSN: 1984-6444 | http://dx.doi.org/10.5902/1984644448673

de uma reserva cognitiva que compensa os efeitos neuropatológicos da doença (CRAIK; BIALYSTOK; FREEDMAN, 2010).

Nos últimos anos, a ideia de que saber mais de uma língua oferece uma maior flexibilidade e um maior ganho cognitivo vem ganhando cada vez mais força, e evidências empíricas vêm endossando esse discurso (LINCK; HOSHINO; KROLL, 2008). Além disso, as demandas mercadológicas, impulsionadas pela globalização, pelo advento da internet e pela comunicação em línguas e em plataformas múltiplas, também são um estímulo forte para o desenvolvimento bilíngue. Os meios de comunicação, as novas mídias, os videogames e a internet, portanto, fornecem uma intensa gama de estímulos multilíngues, que fazem parte do cotidiano da população, acima de tudo dos mais jovens. Isso, por consequência, faz com que "qualquer indivíduo, de forma intencional ou não, incorpore estrangeirismos à sua língua" (GODOY; DIAS, 2014, p. 134), e, assim, se torne, em certo nível, bilíngue, uma vez que este sujeito detém, mesmo que de forma incipiente, o conhecimento e o uso de outra(s) língua(s), principalmente o inglês.

Essa demarcação, por sua vez, não está completamente clara. Há inúmeros debates acadêmicos sobre o que é ser bilíngue e qual o nível de habilidades um usuário deve possuir em uma segunda língua para ter essa característica. Grosjean $(1997$; 2012) contribui nessa discussão, afirmando que muitos mitos ainda circundam o bilinguismo, como o total equilíbrio entre as línguas, a ausência de sotaque, e que bilíngues são sempre ótimos tradutores. Godoy e Dias (2014) concordam com o autor, e ainda comentam que determinar quem é ou não bilíngue é algo complicado de se resolver, uma vez que "não é fácil determinar qual seria o produto final do bilinguismo, uma vez que dificilmente alguém poderá expressar-se de forma igualmente perfeita em duas línguas" (GODOY; DIAS, 2014, p. 134).

No entanto, Finger e Ortiz-Preuss (2018, p. 34), em um trabalho sobre a Psicolinguística do Bilinguismo, elaboraram um quadro que resume e tenta explicar os tipos e níveis de bilinguismo: 


\section{Uism

ISSN: 1984-6444 | http://dx.doi.org/10.5902/1984644448673

Quadro 1 - Tipos e níveis de bilinguismo

\begin{tabular}{|c|c|c|}
\hline ASPECTO & TIPOS DE BILINGUISMO & DESCRIÇÃO \\
\hline \multirow{4}{*}{ Idade } & Precoce & $\begin{array}{l}\text { Aquisição entre } 0 \text { e } 12 \text { anos de } \\
\text { idade }\end{array}$ \\
\hline & Tardio & Aquisição da L2 após os 12 anos \\
\hline & Simultâneo & $\begin{array}{l}\text { Aquisição das duas línguas } \\
\text { desde o nascimento }\end{array}$ \\
\hline & Sucessivo & $\begin{array}{l}\text { Aquisição simultânea de uma } \\
\text { língua após a outra }\end{array}$ \\
\hline \multirow{2}{*}{ Contexto de aquisição } & Composto & $\begin{array}{l}\text { Aquisição das duas línguas e, } \\
\text { muitas vezes, no mesmo } \\
\text { contexto. }\end{array}$ \\
\hline & Coordenado & $\begin{array}{l}\text { Aquisição das duas línguas, } \\
\text { diferentemente, em contextos } \\
\text { separados. }\end{array}$ \\
\hline \multirow{2}{*}{ Grau de uso das línguas } & Dominante & $\begin{array}{l}\text { Nível alto de uso e de proficiência } \\
\text { em uma das línguas. }\end{array}$ \\
\hline & Recessivo & $\begin{array}{l}\text { Dificuldade de compreensão } \\
\text { numa determinada língua, devido } \\
\text { à falta de uso. }\end{array}$ \\
\hline \multirow{3}{*}{$\begin{array}{l}\text { Nível de conhecimento das } \\
\text { línguas }\end{array}$} & Produtivo & $\begin{array}{l}\text { Domínio das habilidades de } \\
\text { produção oral ou escrita em duas } \\
\text { ou mais línguas. }\end{array}$ \\
\hline & Receptivo & $\begin{array}{l}\text { Domínio das habilidades de } \\
\text { compreensão/recepção oral ou } \\
\text { escrita em duas ou mais línguas. }\end{array}$ \\
\hline & Incipiente & $\begin{array}{l}\text { Bilinguismo em fase inicial, pois } \\
\text { uma das línguas ainda está em } \\
\text { fase de desenvolvimento. Pode } \\
\text { ser o caso de aprendizes de L2. }\end{array}$ \\
\hline
\end{tabular}

Fonte: FINGER; ORTIZ-PREUSS, 2018.

Este quadro ilustra a diversidade do bilinguismo. Assim, sugere-se que muitas pessoas, em toda parte do Brasil e do mundo, possuem um grau de bilinguismo que é adquirido a partir das experiências pessoais e culturais, como viagens, experiências 


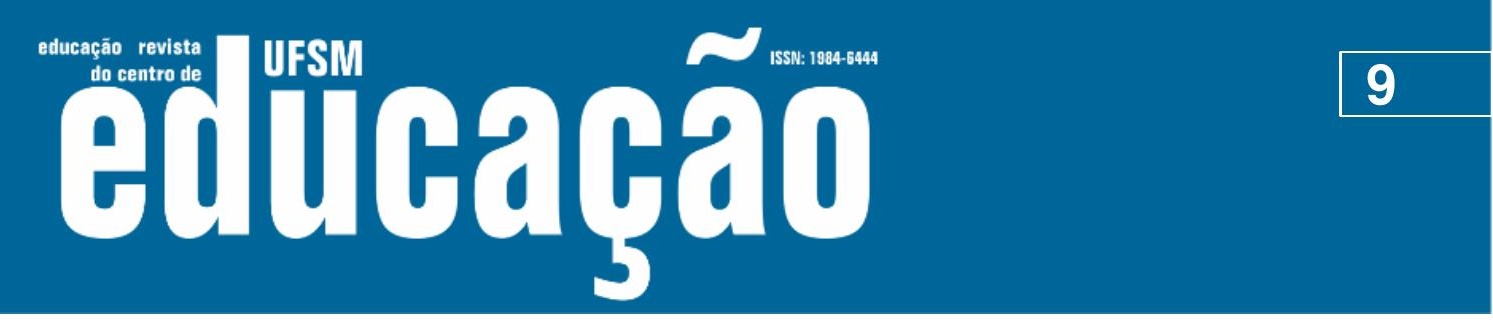

ISSN: 1984-6444 | http://dx.doi.org/10.5902/1984644448673

formativas, como a escola e os cursos de idiomas, e exposições às diferentes línguas existentes por meio das mídias digitais, como celulares, computadores e vídeo games.

$\mathrm{Na}$ escola, o desenvolvimento do bilinguismo, no que tange à língua inglesa, sobretudo nas escolas públicas brasileiras, tem sido um desafio constante. David (2017, p. 83-84) ressalta que, neste aspecto, há

uma imobilidade em relação ao ensino da língua inglesa, advindo de problemas culturais, econômicos e sociais, além das próprias dificuldades do professor em disseminar o conhecimento de um idioma que, muitas vezes, nem faz parte de seu próprio cenário cultural e social.

Este não é um problema exclusivo das escolas públicas, mas afeta estas com mais intensidade. Marzari e Gehres (2015) ainda mencionam que a aprendizagem de uma L2 é afetada por outros fatores, como a falta de material didático apropriado, o constante desinteresse dos alunos pela disciplina e a baixa carga horária destinada ao ensino da L2 na escola. Miranda, Cardoso e Silva (2013) concluem que há, ainda, uma grande distância entre o ideal e o real no ensino de L2. Além disso, as autoras afirmam que há inconsistências no mesmo plano - o ideal e o real - no que concerne aos documentos da educação, como desconexão entre a teoria e a prática.

Em suma, com base no quadro de Finger e Ortiz-Preuss (2018), boa parte dos alunos de inglês das escolas públicas podem ser classificados bilíngues sucessivos, coordenados, recessivos e incipientes. Além disso, pode-se concluir que o proposto nos documentos oficiais dificilmente é aplicado durante as aulas, principalmente devido aos fatores citados por Marzari e Gehres (2015) e David (2017), como a ausência de materiais apropriados, bem como a baixa carga horária da disciplina. É preciso, então, se pensar em como melhorar a performance dos alunos e desenvolver, de uma maneira mais sólida, a sua L2. Neste sentido, uns dos elementos principais é o trabalho com a leitura.

\section{Leitura e Estratégias de Leitura: uma breve discussão}

Alguns autores, como Souza e Garcia (2012), concebem a leitura como algo tão complexo que a metaforizam como a natação para o cérebro. Izquierdo (2018, p. 98), por sua vez, destaca que "não há outra atividade nervosa que exija tanto em tão 


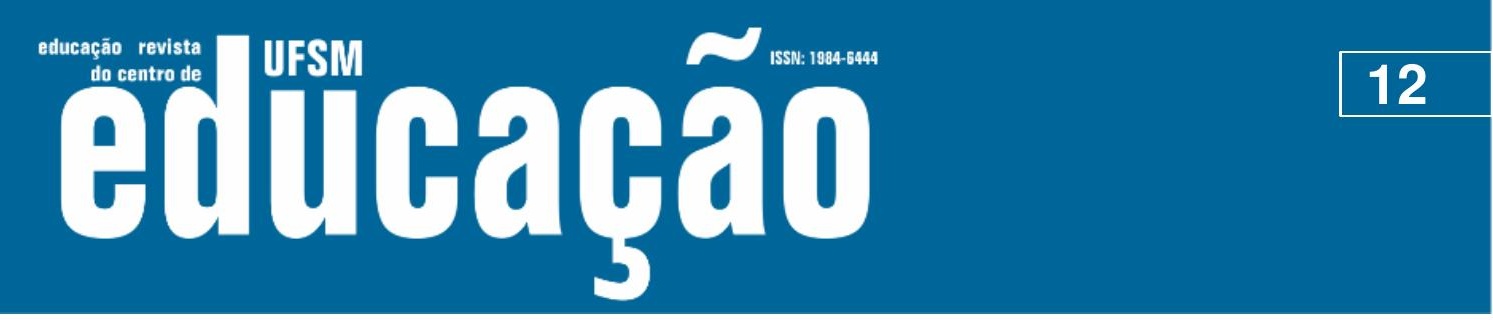

ISSN: 1984-6444 | http://dx.doi.org/10.5902/1984644448673

\section{Leitura em L2: caminhos para se compreender diferentes códigos}

A leitura é uma atividade dinâmica, que exige do indivíduo processamentos cognitivos de níveis mais altos e mais baixos para se atingir a compreensão de um texto. A leitura em uma L2 não é diferente: ela mantém essas demandas, e faz com que o leitor se esforce mentalmente para entender o que traz o código. Porém, para além da leitura na primeira língua (L1), a da segunda contém peculiaridades adicionais.

Uma das muitas especificidades da leitura em L2 é a sua complexidade. Todavia, não se fala, neste momento, da complexidade inerente ao ato de ler, como na L1, mas de um nível de dificuldade que se torna ainda maior, pelo fato do leitor ter que administrar em sua mente não mais apenas um código, mas dois. Isso traz à tona alguns questionamentos, como: qual das duas línguas é acionada na hora da leitura?

Para responder a essa pergunta é preciso voltar aos debates levantados por Grosjean (2012), o qual diz que, ao se comunicar, o bilíngue não é seletivo com relação às suas línguas. Embora ele esteja utilizando a L2, a sua L1 continua ativa, 0 que o pesquisador chama de modo bilíngue (GROSJEAN, 2012). O mesmo acontece com a leitura: pode-se dizer que ela também possui um caráter não-seletivo (CASAPONSA; CARREIRAS; DUÑABEITIA, 2015; MIWA et al., 2014). Em outras palavras, quando o leitor bilíngue toma um texto para leitura na sua $L 2$, a sua $L 1$, da mesma forma, continuará ativa, interagindo com a outra para sugerir opções de elementos fonológicos, ortográficos e semânticos para constituir a compreensão.

Conforme mencionado, a L1 tem papel ativo na leitura da L2. Este é um papel fundamental, uma vez que a $L 2$ pode usar a primeira como apoio na compreensão, algo que é natural e automático (VASSEUR, 2013). Assim, o leitor pode utilizar-se da sua L1 para levantar hipóteses sobre a L2, observando similaridades e realizando inferências a partir do que associa entre os códigos (KLEIMAN, 2011; KATO, 1999).

Neste sentido, em estudos antecedentes, muito se discutia sobre a questão da transferência linguística entre os idiomas; ou seja, se as habilidades da L1 eram transferidas para a L2 (GASS; SELINKER, 1983). Essa noção de que a L1 passa para L2 os seus padrões semelhantes foi aos poucos sendo substituída pela ideia de 


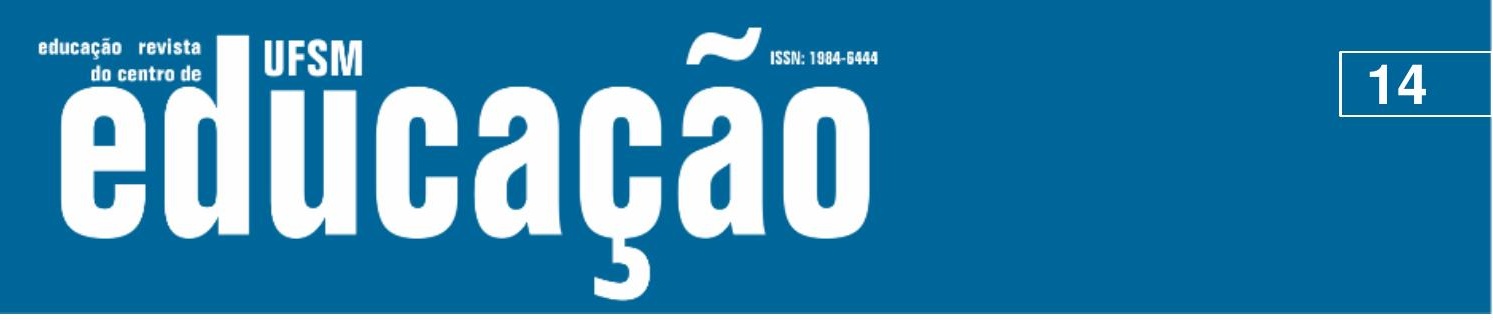

ISSN: 1984-6444 | http://dx.doi.org/10.5902/1984644448673

são acolhidos e legitimados os usos que dela fazem falantes espalhados no mundo inteiro, com diferentes repertórios linguísticos e culturais, o que possibilita, por exemplo, questionar a visão de que o único inglês "correto" e a ser ensinado - é aquele falado por estadunidenses ou britânicos (BRASIL, 2017, p. 241).

Desta forma, em uma primeira impressão, o documento parece dar ao ensinoaprendizagem do inglês como L2 um caráter democrático, que valoriza a diversidade dos sotaques e dos regionalismos, que, de acordo com o documento, influenciaram a criação dos cinco eixos organizadores: Oralidade, Leitura, Escrita, Conhecimentos Linguísticos e Dimensão Intercultural (BRASIL, 2017, grifo nosso).

Embora a BNCC trate, de maneira específica, sobre o desenvolvimento da L2 no Ensino Fundamental, os termos bilíngue e bilinguismo não são utilizados no documento, salvo por quando faz alusão ao trabalho com as línguas indígenas. Ali, ressalta-se a importância de um currículo bilíngue, no qual garante-se o ensino da língua portuguesa, bem como o da respectiva língua indígena, preservando os aspectos culturais desta (BRASIL, 2017). Isso pode transparecer que o próprio documento não vê o ensino da L2 na escola regular como uma possibilidade de se formar alunos bilíngues competentes, ou mesmo não vê o bilinguismo como um fenômeno de diferentes apresentações e níveis de fluência (FINGER; ORTIZPREUSS, 2018), que podem ser aprimorados gradualmente por meio de práticas significativas. Apesar de não tratar sobre bilinguismo propriamente dito, porém, o documento discorre sobre o desenvolvimento do inglês como L2, por meio dos eixos organizadores supracitados.

Quando se analisam os cinco eixos, os quais são a base geral para 0 desenvolvimento da segunda língua, segundo a BNCC, percebe-se que abrangem as quatro habilidades básicas do aprendizado de L2 já comumente conhecidas, também debatidas por Baker (2001), que são: audição, fala, leitura e escrita. O documento não se atém apenas às quatro habilidades, e incorpora a elas os Conhecimentos Linguísticos (aqui referindo-se ao estudo da língua, com foco na gramática) e a Dimensão Intercultural, que, segundo a BNCC (2017, p. 245) implica em 


\section{$\sim 7$

ISSN: 1984-6444 | http://dx.doi.org/10.5902/1984644448673

demais $\left(7^{\circ}, 8^{\circ}\right.$ e $9^{\circ}$ ano). O quadro a seguir ilustra os componentes do eixo leitura para o 6ำ ano (BRASIL, 2017):

Quadro 2 - Componentes do eixo leitura para o 6ํano

\begin{tabular}{|c|c|}
\hline UNIDADES TEMÁTICAS & OBJETOS DE CONHECIMENTO \\
\hline & Hipóteses sobre a finalidade de um texto \\
\hline Estratégias de Leitura & $\begin{array}{c}\text { Compreensão geral e específica: leitura rápida } \\
\text { (skimming, scanning) }\end{array}$ \\
\hline $\begin{array}{l}\text { Práticas de leitura e construção de repertório } \\
\text { lexical }\end{array}$ & $\begin{array}{c}\text { Construção de repertório lexical e autonomia } \\
\text { leitora }\end{array}$ \\
\hline Atitudes e disposições favoráveis do leitor & Partilha de leitura, com mediação do professor \\
\hline
\end{tabular}

Fonte: BRASIL, 2017.

As estratégias de leitura foram apresentadas como um tema mais abrangente, e depois detalhadas como objetos de conhecimento, ou conteúdos a serem desenvolvidos em sala de aula. Entende-se, neste trabalho, que sim, estratégias precisam ser ensinadas, conforme postulam Souza e Garcia (2012), mas não como conteúdos específicos, conforme traz o documento. É importante que os alunos consigam compreender um texto de maneira geral, utilizando o skimming e o scanning, mas estas são habilidades que eles podem desenvolver, e não algo que consta no currículo e que depois subentende-se de que pode ser cobrado de modo avaliativo. Em suma, é mais adequado que o que está colocado como objeto de conhecimento esteja, na verdade, configurado como habilidade do que como conteúdo. Tais estratégias precisam ser trabalhadas constantemente em sala de aula, com vistas a formar um leitor habilidoso e competente, e não de maneira estática, fazendo com que o aluno muitas vezes lembre-se temporariamente, e depois se esqueça (SANTOS, 2013). 


\section{OF LFH eltibagáó}

ISSN: 1984-6444 | http://dx.doi.org/10.5902/1984644448673

Já nas habilidades, o documento é mais coerente com a proposta deste trabalho. Ele menciona, como uma das habilidades de leitura, que o aluno possa "formular hipóteses sobre a finalidade de um texto em língua inglesa, com base em sua estrutura, organização textual e pistas gráficas" (BRASIL, 2017, p. 249), que é a proposta do skimming, uma das estratégias de pré-leitura (SANTOS, 2013; ALLIENDE; CONDEMARÍN, 2005). Ou seja, estratégias sendo utilizadas como habilidades para o desenvolvimento da leitura proficiente, não como conteúdo fixo a ser ensinado em sala de aula.

No $7^{0}$ ano, há poucas mudanças. O quadro a seguir demonstra as regulamentações no eixo leitura para esta fase escolar (BRASIL, 2017):

Quadro 3 - Componentes do eixo leitura para o $7^{\circ}$ ano

\begin{tabular}{|c|c|}
\hline UNIDADES TEMÁTICAS & OBJETOS DE CONHECIMENTO \\
\hline \multirow{2}{*}{ Estratégias de Leitura } & $\begin{array}{r}\text { Compreensão geral e específica: leitura rápida } \\
\text { (skimming, scanning) }\end{array}$ \\
\cline { 2 - 2 } & Construção do sentido global do texto \\
\hline Práticas de leitura e pesquisa & Objetivos de leitura \\
\cline { 2 - 2 } & Leitura de textos digitais para estudo \\
\hline Atitudes e disposições favoráveis do leitor & Partilha de leitura \\
\hline
\end{tabular}

Fonte: BRASIL, 2017.

Aqui nota-se que foi feito o mesmo com relação ao $6^{\circ}$ ano: as estratégias de skimming e de scanning estão postas como objetos de conhecimento, e não como habilidades de estudo. Além disso, fica o questionamento (que não foi mencionado na última análise, mas que também está presente no ano anterior), sobre o que se pretende com a unidade temática Atitudes e disposições favoráveis do leitor, uma vez que existem diferentes modos de se abordar um texto, e, da mesma forma, diferentes atitudes e comportamentos de leitores (conforme FOUCAMBERT, 2008). 


\section{Eulloarão

ISSN: 1984-6444 | http://dx.doi.org/10.5902/1984644448673

As habilidades a serem desenvolvidas no $7^{\circ}$ ano são mais condizentes com a teoria na área, uma vez que permitem ao aluno, por exemplo, mobilizar conhecimentos prévios, identificar o(s) objetivo(s) de um texto, fazer inferências para antecipar o sentido global de um texto, relacionar partes dele para formar um todo, entre outras estratégias inerentes ao desenvolvimento da leitura fluente e precisa.

No $8^{\circ}$ ano, as mudanças são mais perceptíveis. O quadro abaixo ilustra as modificações realizadas no documento com o passar da fase escolar (BRASIL, 2017):

Quadro 4 - Componentes do eixo leitura para o 8ํao $^{\circ}$

\begin{tabular}{|c|c|}
\hline UNIDADES TEMÁTICAS & OBJETOS DE CONHECIMENTO \\
\hline Estratégias de Leitura & $\begin{array}{r}\text { Construção de sentidos por meio de inferências } \\
\text { e reconhecimento de implícitos }\end{array}$ \\
\hline Práticas de leitura e fruição & Leitura de textos de cunho artístico/literário \\
\hline Avaliação dos textos lidos & Reflexão pós-leitura \\
\hline
\end{tabular}

Fonte: BRASIL, 2017.

Nesta fase, além da estratégia de inferência ser colocada como objeto de conhecimento, há uma segunda inconsistência, que é a falta de clareza do texto. De um ano para outro, existe a percepção de que os temas estão reduzidos e pouco objetivos. Fica o questionamento sobre que tipo de reflexão se está sugerindo, uma vez que a palavra reflexão é abrangente. Observa-se, aqui, também, um caráter reducionista dado ao processo complexo que é a leitura, que é impresso na prática pedagógica do professor, que é o principal usuário deste documento. Neste sentido, para Kleiman (2011 , p. 19), "se o professor não perceber a complexidade do processo de leitura, e da interação, ele estará, na maioria das vezes, ecoando acriticamente comentários alheios, sem conseguir implementar essa visão, verbalizando sem agir". Por isso, é importante que a BNCC seja clara, objetiva e justa com relação aos processos de leitura em L2, ou, ao invés disso, estará, conforme destaca Ribas (2018, 


\section{F USM eltubaráo}

ISSN: 1984-6444 | http://dx.doi.org/10.5902/1984644448673

p. 1817), reforçando "o apagamento de questões sociopolíticas que impactam o ensino e a aprendizagem de uma língua".

No que tange às habilidades no $8^{\circ}$ ano, o documento é um pouco mais adequado, mas ainda assim reduzido e redundante com relação ao ano anterior, quando declara que uma habilidade necessária ao aprendiz de inglês como L2, em termos de leitura, é a de "inferir informações e relações que não aparecem de modo explícito no texto para construção de sentidos" (BRASIL, 2017, p. 257).

As determinações para o $9^{\circ}$ ano seguem os mesmos parâmetros do ano anterior, com poucas elucidações e com escolhas lexicais de caráter ambíguo. O quadro a seguir apresenta mais detalhes, de acordo com a BNCC (BRASIL, 2017):

Quadro 5 - Componentes do eixo leitura para o 9ํano

\begin{tabular}{|c|c|}
\hline UNIDADES TEMÁTICAS & OBJETOS DE CONHECIMENTO \\
\hline \multirow{2}{*}{ Estratégias de Leitura } & Recursos de persuasão \\
\cline { 2 - 2 } & Recursos de argumentação \\
\hline Práticas de leitura e novas tecnologias & Informações em ambientes virtuais \\
\hline Avaliação dos textos lidos & Reflexão pós-leitura \\
\hline
\end{tabular}

Fonte: BRASIL, 2017.

Este quadro leva o leitor a pensar sobre quais estratégias o documento se refere quando menciona os recursos de persuasão e de argumentação; se estes tratam de identificação de objetivos do autor com o texto, se a ideia é o estudante identificar quais elementos compõem o discurso persuasivo e o argumentativo, entre outras possibilidades. Assim como em outros anos escolares, o texto aqui não é muito claro, e o leitor pode interpretar, com isso, que há pouco conhecimento específico da área em questão, uma vez que os termos escolhidos são abrangentes e dão margem a uma série de ramificações conceituais (como acontece, novamente, com a reflexão pós-leitura). Além disso, conforme já afirmado na análise dos outros anos escolares, não cabe aqui selecionar estratégias como objetos de conhecimento, mas como 


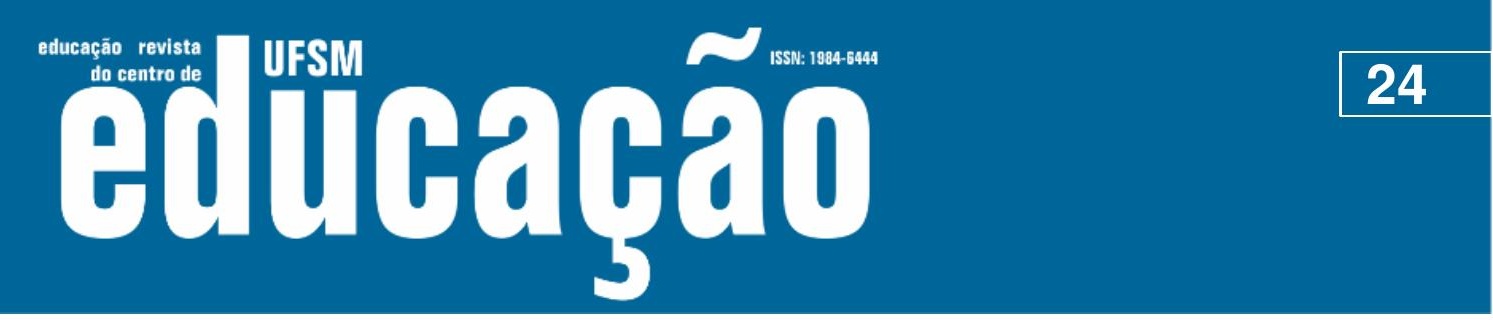

ISSN: 1984-6444 | http://dx.doi.org/10.5902/1984644448673

de fato, promover o aprendizado significativo do aluno e torná-lo bilíngue. Além disso, é preciso que, futuramente, o documento seja reformulado, a partir de bases teóricas sólidas, de modo a excluir as incoerências e o caráter normativo, devolvendo ao professor a autonomia como profissional e como criador e modificador da sua prática.

\section{Referências}

ADOLPHS, Svenja et al. Digital innovations in L2 motivation: harnessing the power of the Ideal L2 Self. System, v. 78, p. 173-185, 2018.

ALLIENDE, Felipe; CONDEMARÍN, Mabel. A leitura: teoria, avaliação e desenvolvimento. Porto Alegre: Artes Médicas, 2005.

ARAÚJO, Antonia Dilamar. Leitura de textos eletrônicos: diagnosticando estratégias de compreensão. In: TOMITCH, Lêda Maria Braga (org.). Aspectos cognitivos e instrucionais da leitura. Bauru, SP: EDUSC, 2008.

BADDELEY, Alan. Memória de trabalho. In: BADDELEY, Alan; ANDERSON, Michael C.; EYSENCK, Michael. Memória. Tradução de Cornélia Stolting. Porto Alegre: Artmed, 2011.

BAKER, Colin. Foundations of bilingual education and bilingualism. $3^{\mathrm{a}}$ ed. Clevedon: Multilingual Matters, 2001.

BAKER, Linda; BROWN, Ann L. Metacognitive skills and reading. Eric. 1980. Disponível em: https://files.eric.ed.gov/fulltext/ED195932.pdf. Acesso em: 11 jan. 2020.

BIALYSTOK, Ellen et al. Bilingual minds. Psychological Science in the Public Interest, v. 10, n. 3. 2009.

BRANCO, Alessandra Batista de Godoi et al. Urgência da Reforma do Ensino Médio e emergência da BNCC. Revista Contemporânea de Educação. v. 14, n. 29. 2019. Disponível em: https://revistas.ufrj.br/index.php/rce/article/view/22187. Acesso em: 07 jan. 2020.

BRASIL. Secretaria de Educação Fundamental. Parâmetros Curriculares Nacionais: Introdução aos Parâmetros Curriculares Nacionais. MEC/SEF, 1997. Disponível em: http://portal.mec.gov.br/seb/arquivos/pdf/livro01.pdf. Acesso em: 06 jan. 2020. 


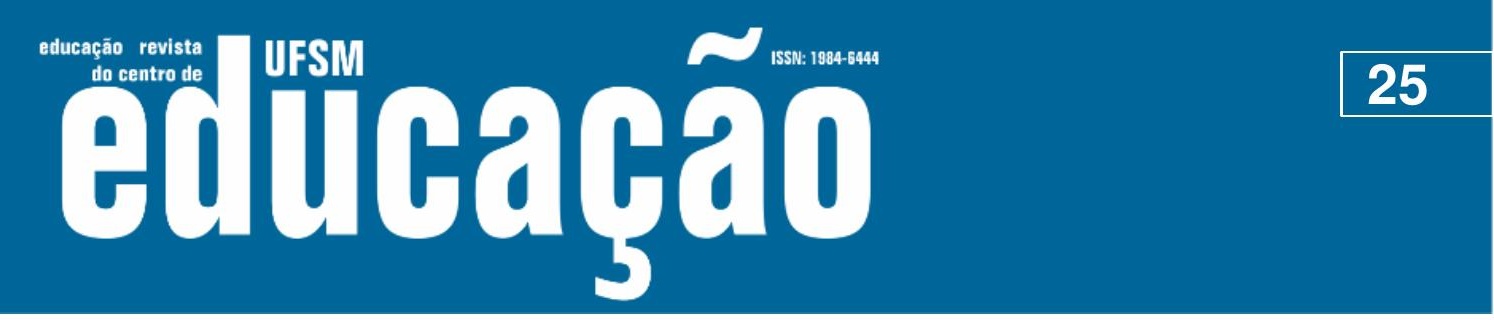

ISSN: 1984-6444 | http://dx.doi.org/10.5902/1984644448673

BRASIL. Secretaria de Educação Fundamental. Parâmetros Curriculares Nacionais: Terceiro e Quarto ciclos do Ensino Fundamental: Língua Estrangeira. MEC/SEF, $1998 . \quad$ Disponível em: http://portal.mec.gov.br/seb/arquivos/pdf/pcn_estrangeira.pdf. Acesso em: 06 jan. 2020.

BRASIL. Ministério da Educação. Diretrizes Curriculares Nacionais Gerais da Educação Básica. Brasília: MEC/SEB/DICEI, 2013. Disponível em: http://portal.mec.gov.br/docman/julho-2013-pdf/13677-diretrizes-educacao-basica2013-pdf/file. Acesso em: 06 jan. 2020.

BRASIL. Ministério da Educação. Base Nacional Comum Curricular: Educação é a Base. Brasília, 2017. Disponível em: http://basenacionalcomum.mec.gov.br/images/BNCC_EI_EF_110518_versaofinal_sit e.pdf. Acesso em: 06 jan. 2020.

CASAPONSA, Aina; CARREIRAS, Manuel; DUÑABEITIA, Jon Andoni. How do bilinguals identify the language of the words they read? Brain Research, v. 1624, p. 153-166. 2015.

CRAIK, Fergus I. M.; BIALYSTOK, Elen; FREEDMAN, Morris. Delaying the onset of Alzheimer disease: bilingualism as a form of cognitive reserve. Neurology, v. $75, \mathrm{n}$. 19, p. 1726-1729. 2010.

DAVID, Ricardo Santos. O ensino-aprendizagem de língua inglesa em escolas públicas: o real e o ideal. Revista Pedagogia em Ação. v. 9, n. 1. 2017. Disponível em: $\quad$ http://periodicos.pucminas.br/index.php/pedagogiacao/article/view/13741. Acesso em: 09 jan. 2020.

DEWAELE, Jean-Marc. Psychological and sociodemographic correlates of communicative anxiety in L2 and L3 production. International Journal of Bilingualism, v. 6, n. 1. 2002.

FINGER, Ingrid; BRENTANO, Luciana; ARÊAS DA LUZ FONTES, Ana Beatriz. Neurociências, psicolinguística e aprendizagem de Línguas Adicionais: um diálogo necessário no contexto da educação do século 21. In: MAIA, Marcus (org.). Psicolinguística e Educação. Campinas, SP: Mercado de Letras, 2018.

FINGER, Ingrid; ORTIZ-PREUSS, Elena. A psicolinguística do bilinguismo: estudando o processamento linguístico e cognitivo bilíngue. In: FINGER, Ingrid; ORTIZ-PREUSS, Elena. A dinâmica do processamento bilíngue. Campinas: Pontes, 2018. 


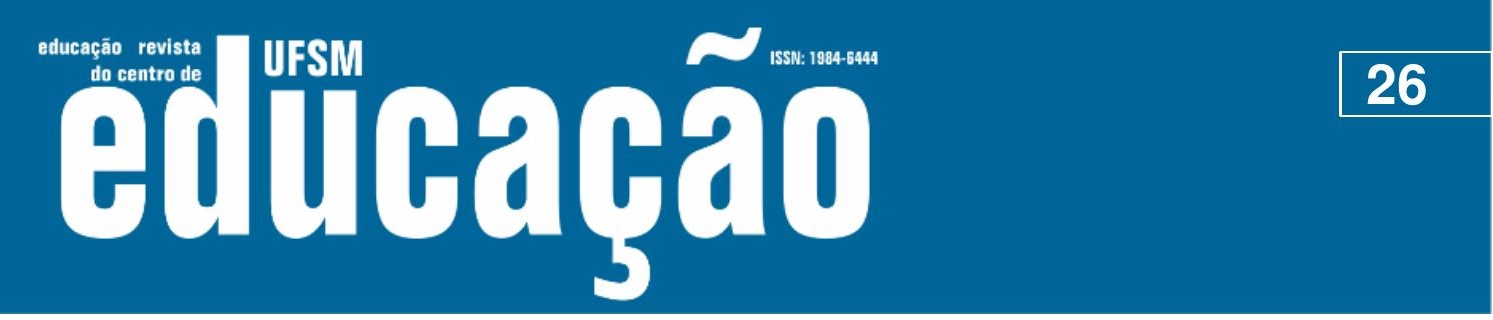

ISSN: 1984-6444 | http://dx.doi.org/10.5902/1984644448673

FISTAROL, Caique Fernando da Silva; FISCHER, Adriana; WENDERLICH, Rosana Clarice Coelho. A Base Nacional Comum Curricular e a formação de professores de língua inglesa: desafios e possibilidades. Revista de Política e Gestão Educacional, v. 23, n. 2, p. 341-355. 2019. Disponível em: https://periodicos.fclar.unesp.br/rpge/article/view/12453. Acesso em: 24 jun. 2020.

FOUCAMBERT, Jean. Modos de ser leitor. Curitiba: Editora da UFPR, 2008.

GARDNER, Amanda. Revising integrative motivation: L2 motivation research and learner context. Working Papers in TESOL \& Applied Linguistics, 2010. Disponível em: https://academiccommons.columbia.edu/doi/10.7916/D84B30WH. Acesso em: 24 jun. 2020.

GASS, Susan; SELINKER, Larry. Language transfer in language learning. Rowley: Newbury House, 1983.

GODOY, Elena; DIAS, Luzia SCHAUKOSKI. Psicolinguística em foco: linguagem aquisição e aprendizagem. Curitiba: InterSaberes, 2014.

GROSJEAN, François. The bilingual individual. Revista Interpreting. p. 163-187. 1997. Disponível em: https://www.francoisgrosjean.ch/bilin_bicult/5\%20Grosjean.pdf. Acesso em: 10 jan. 2020.

GROSJEAN, François. Bilingualism: a short introduction. In: GROSJEAN, François; $\mathrm{LI}$, Ping. The Psycholinguistics of Bilingualism. Hoboken, NJ: John Wiley \& Sons, 2012. p. 5-25.

GUIMARÃES, lara Vieira. Ensinar e aprender Geografia na Base Nacional Comum Curricular (BNCC). Revista Ensino em Re-Vista. v. 25. 2018.

IZQUIERDO, Ivan. Memória. Porto Alegre: ArtMed, 2018.

KATO, Mary. O aprendizado da leitura. São Paulo: Martins Fontes, 1999.

KLEIMAN, Angela. Estratégias de inferência lexical na leitura de segunda língua. Revista Ilha do Desterro. p. 67-82. 1985. Disponível em: https://periodicos.ufsc.br/index.php/desterro/article/view/9026. Acesso em: 11 jan. 2020.

KLEIMAN, Angela. Oficina de leitura: teoria e prática. Campinas, SP: Pontes, 2013.

KLEIMAN, Angela. Leitura: ensino e pesquisa. Campinas, SP: Pontes, 2011.

LEFFA, Vilson José. Aspectos da leitura: uma perspectiva psicolinguística. Porto Alegre: Sagra-Luzzatto, 1996. 


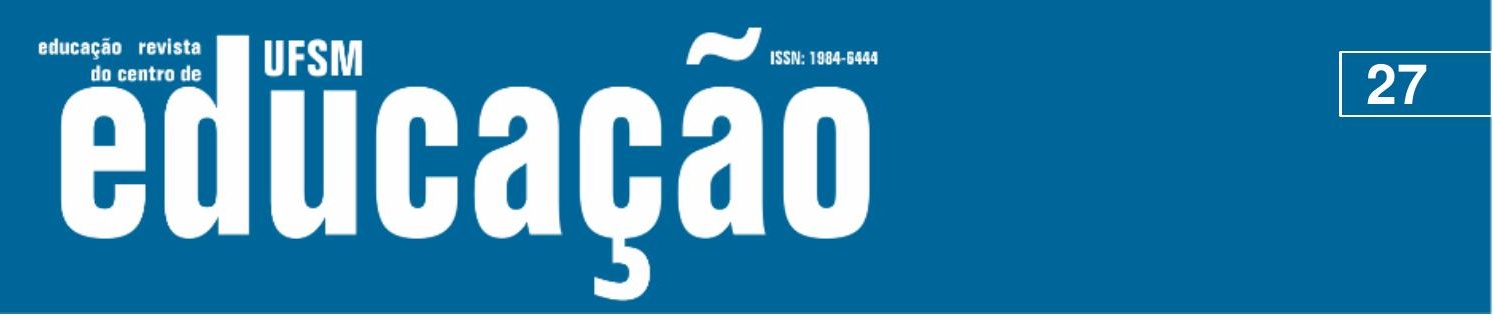

ISSN: 1984-6444 | http://dx.doi.org/10.5902/1984644448673

LINCK, Jared A. KOSHINO, Noriko; KROLL, Judith F. Cross-language lexical processes and inhibitory control. Ment. Lex., v. 3, n. 3, p. 349-374. 2008.

MARTINELI, Telma Adriana Pacífico et al. A Educação Física na BNCC: concepções e fundamentos políticos e pedagógicos. Revista Motrivivência. v. 28, n. 48, p. 76-95. 2016.

MARZARI, Gabriela Quatrin; GEHRES, Wilma Beatriz Schultz. Ensino de Inglês na escola pública e suas possíveis dificuldades. Revista Thaumazein. v. 7, n. 14, p. 1219.2015 .2 Disponível em: https://periodicos.ufn.edu.br/index.php/thaumazein/article/view/214. Acesso em: 09 jan. 2020.

MICARELLO, Hilda Aparecida Linhares da Silva. A BNCC no contexto de ameaças ao estado democrático de direito. Revista EccoS. n. 41, p. 61-75. 2016.

MIRANDA, Cristina Helena; CARDOSO, Patrícia Silva; SILVA, Marimar da. "Você aprende inglês na escola?" "Daquele jeito, né?": percepções sobre o ensinoaprendizagem de Língua Estrangeira na escola pública. Revista Fórum Linguístico. v. 10 , n. 4 , p. 307-328. 2013.

MIWA, Koji et al. Reading english with japanese in mind: effects of frequency, phonology, and meaning in different-script bilinguals. Bilingualism: language and cognition, v. 17, n. 3, p. 445-463. 2014.

MOTA, Mailce Borges; MASCARELLO, Lidiomar José; BUCHWEITZ, Augusto. Memória de Trabalho e dificuldades de aprendizagem da leitura no $2^{\circ}$ ano do Ensino Fundamental: os resultados de uma intervenção. In: MAIA, Marcus (org.). Psicolinguística e Educação. Campinas, SP: Mercado de Letras, 2018.

NEIRA, Marcos Garcia; ALVIANO JÚNIOR, Wilson; ALMEIDA, Déberson Ferreira de. A primeira e segunda versões da BNCC: construção, intenções e condicionantes. Revista EccoS, n. 41, p. 31-44, 2016.

OLIVEIRA, Sara. Hipertexto e aspectos afetivos. In: TOMITCH, Lêda Maria Braga (org.). Aspectos cognitivos e instrucionais da leitura. Bauru, SP: EDUSC, 2008.

ORNELLAS, Janaína Farias de; SILVA, Luana Cristeinsen. O Ensino Fundamental da BNCC: proposta de um currículo na contramão do conhecimento. Revista Espaço do Currículo. v. 12, n. 2, p. 309-325. 2019. Disponível em: https://periodicos.ufpb.br/index.php/rec/article/view/ufpb.19831579.2019v12n2.43516. Acesso em: 08 jan. 2020.

ORRÚ, Sílvia Ester. Base Nacional Comum Curricular: à contramão dos espaços de aprendizagem inovadores e inclusivos. Revista Tempos e Espaços em Educação. v.11, n. 25. p. 141-154. 2018. 




ISSN: 1984-6444 | http://dx.doi.org/10.5902/1984644448673

RIBAS, Fernanda Costa. Base Nacional Comum Curricular e o ensino de língua inglesa: refletindo sobre cidadania, diversidade e criticidade à luz do Letramento Crítico. Revista Domínios de Linguagem. v. 12, n. 3. 2018.

SANTOS, Denise. Ensino de Língua Inglesa: foco em estratégias. São Paulo: Disal, 2013.

SCHROTER, Pauline; SCHROEDER, Sascha. Orthographic processing in balanced bilingual children: Cross-language evidence from cognates and false friends. Journal of Experimental Child Psychology, v. 141, p. 239-246. 2016.

SILVA, Marcos. "Tudo que você consegue ser": Triste BNCC/História. Revista Ensino em Re-Vista. v. 25, p. 1004-1015. 2018. Disponível em: http://www.seer.ufu.br/index.php/emrevista/article/view/46454. Acesso em: 07 jan. 2020.

SMITH, Frank. Compreendendo a leitura: uma análise psicolinguística da leitura e do aprender a ler. Porto Alegre: Artes Médicas, 2003.

SOLÉ, Isabel. Estratégias de leitura. Tradução de Cláudia Schilling. Porto Alegre: ArtMed, 1998.

SOUZA, Ana Cláudia de; GARCIA, Wladimir Antônio da Costa. A produção de sentidos e o leitor: os caminhos da memória. Florianópolis: NUP/CED/UFSC, 2012.

SOUZA, Ana Cláudia de; SALETE, Maria. O professor leitor e o ensino da competência leitora. Revista Signo. V. 43, n. 77, p. 143-159. 2018.

SPARKS, Richard L.; PATTON, Jon. Relationship of L1 skills and L2 aptitude to L2 anxiety on the foreign language classroom anxiety scale. Language Learning, v. 63, n. 4, p. 870-895. 2013.

VASSEUR, Marie-Thérèse. Aquisição de L2: compreender como se aprende para compreender o desenvolvimento da competência em interagir em L2. In: DEL RÉ, Alessandra (org.). Aquisição da linguagem: uma abordagem psicolinguística. $2^{\mathfrak{a}}$ ed. São Paulo: Contexto, 2013. p. 85-112.

WALTER, Catherine. First to second language reading comprehension: not transfer, but access. International Journal of Applied Linguistics, v. 17, n. 1, p. 14-37. 2007.

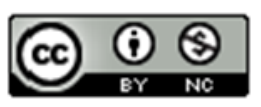

This work is licensed under a Creative Commons Attribution-NonCommercial 4.0 International (CC BY-NC 4.0) 


\section{usp \\ ISSN: 1984-6444

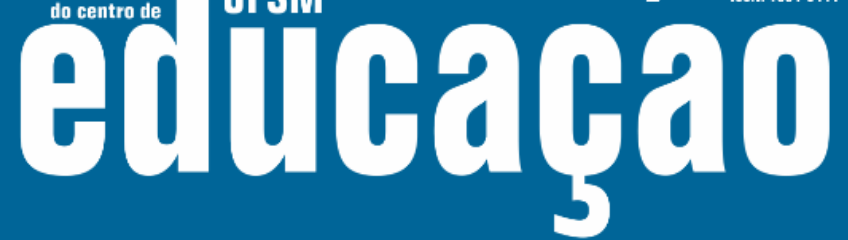

ISSN: 1984-6444 | http://dx.doi.org/10.5902/1984644448673

\section{Nota}

$1 \mathrm{O}$ documento traz o termo Língua Estrangeira, pois envolve todo o conjunto de línguas que pode ser ensinado na escola. Entretanto, neste trabalho, adota-se o termo Segunda Língua (L2), e dá-se ênfase ao inglês. A BNCC, por sua vez, não utiliza termos como língua estrangeira, L2 ou língua adicional, uma vez que aborda especificamente o ensino-aprendizagem da língua inglesa, e, por isso, usa esta expressão no corpo do texto. 